\title{
A AMAZÔNIA E A POLÍTICA AMBIENTAL BRASILEIRA*
}

\author{
BERTHA K. BECKER \\ Universidade Federal do Rio de Janeiro
}

Quando a tecnologia dos satélites permitiu ao homem olhar a terra a partir do Cosmos, houve uma verdadeira revolução no sentido da percepção sobre o Planeta: passou-se a ter consciência da sua unidade. É importante lémbrar que não se tinha, até recentemente, essa visão da unidade do Planeta. Começou-se a ter noção do conjunto planetário com a expansão da navegação a vapor, com as ferrovias e, depois, com o avião. Isso, praticamente, no século XIX; antes, conheciamse apenas pedaços da superfície da Terra. Não se tinha essa noção do conjunto, da unidade do Planeta. E essa visão de fora foi extraordinária, porque se passou a ter a consciência da unidade e, também, ao mesmo tempo, a percepção de que a natureza tornara-se um bem escasso. Isso teve um impacto enorme. Assim, é muito importante chamar a atenção sobre essa mudança das percepções de mundo a partir do avanço da tecnologia.

Outro ponto interessante a destacar é aquele em relação à afirmação de Yuri Gagárin, ao ver nosso planeta do espaço, dizer que a Terra era azul. Na verdade, se mudarmos de escala, diminuindo-a um pouco, ou talvez até mesmo na mesma escala, sob outra perspectiva, descobriremos um imenso coração verde na Terra, e este coração é a Amazônia. Descendo ainda mais um pouco e mudando novamente a escala, veremos que essa grande mancha verde, esse heartland - coração verde da Terra - na verdade não é homogêneo: existe uma diversidade dentro dessa unidade, começando pela diversidade dos ecossistemas e passando pela diversidade cultural que existe na região. Queremos com isto destacar duas questões geográfi-

\footnotetext{
* Conferência proferida por ocasião da abertura do Curso de Doutorado em Geografia no Programa de Pós-Graduação em Geografia da Universidade Federal Fluminense, Niterói, maio de 2002.
} 
cas de grande relevância: a questão da mudança de percepção com o avanço da tecnologia e a questão das escalas, extremamente importante na nossa disciplina, um dos trunfos que temos em relação a outras áreas e que não podemos perder, ou seja, os territórios e suas diferentes escalas.

É claro que não é só a tecnologia que muda a percepção do espaço. Estas percepções variam com os interesses humanos, e são, via de regra, interesses conflitivos, e conflitivas, portanto, as percepções e as ações que decorrem desses interesses. A tecnologia é um elemento, um elemento da globâlização. Este avanço da tecnologia dos satélites é um aspecto da globalização que não tem sido suficientemente explorado. Mas ele não é, absolutamente, o único. É um elemento dentre outros. O que vale são os diferentes interesses, motivações, e como estes interesses e motivações se transmitem através de ações e como rebatem no espaço planetário e nos territórios.

Estou chamando a atenção para isso porque quero dizer que a Amazônia brasileira, nos últimos anos, passou por profundas transformações, e porque existem muitos mitos em relação à Amazônia. É importante reconhecer isso, uma vez que, num processo repleto de sangue, suor e lágrimas, como foi o processo de ocupação da Amazônia, na década de 70 e começo dos anos 80 , surgiram também mudanças estruturais, fundamentais, na região. E, se nós não reconhecermos essas mudanças estruturais, não vamos entender os processos que estão em curso e nem vamos poder fazer uma reflexão para subsidiar políticas mais conseqüentes para a região.

Como geógrafa política, estou falando de mudanças estruturais. Podemos perguntar, então: afinal de contas, que mudanças estruturais são essas? Em primeiro lugar, há uma mudança na conectividade - a Amazônia, até as décadas de 50, 60, era uma grande ilha, praticamente voltada para o exterior, desligada do território nacional, como ocorria no antigo "arquipélago" brasileiro. A conectividade de que mais se ouve falar é a conectividade promovida pelas estradas. A mais importante, porém, é a conectividade pela rede de telecomunicações, que foi vital para a Amazônia, permitindo conectar-se com o resto do território nacional e com o exterior. Ela foi base de parcerias que se organizam hoje em várias escalas, do nível local ao regional, nacional e internacional.

Uma outra mudança estrutural importantíssima foi a econômica, porque se tratava de uma área de extrativismo que, agora, possui uma indústria relativamente importante, com impactos negativos muito conhecidos. A Amazônia ocupa hoje o segundo lugar no país na produção mineral e o terceiro na produção de bens de consumo duráveis.

Outra mudança fundamental ocorreu na estrutura do povoamento, que era toda fundamentada ao longo dos rios e que, hoje em dia, se desenvolve ao longo das estradas implantadas na região, mas, sobretudo, mudança na estrutura do povoamento no que se refere ao processo de urbanização. Muito se falou na expansão da fronteira agrícola, mas ela foi sempre o início de uma fronteira urbana, porque o urbano precedeu a própria expansão agrícola. Os núcleos urbanos eram os 
núcleos de agregação, de mobilização da força de trabalho, da mão-de-obra, e era aí que os "gatos" vinham pegar os peões, os núcleos urbanos foram fundamentais para a devastação da floresta e na expansão da pecuária. Portanto, não era uma fronteira para a produção agrícola no sentido em que comumente se pensa o espaço agrário. Hoje, de acordo com o censo de 2000 , 69,07\% da população, na Região Norte é urbana. A Amazônia é uma floresta urbana. Voltaremos a este ponto mais à frente.

O mais importante em todo esse processo é a mudança na organização da sociedade, é a mudança na sociedade da Amazônia. Esta é a base de todo processo e veio ligada às grandes mazelas da região: as telecomunicações, a mobilidade do trabalho, a urbanização. $\mathrm{O}$ fato é que houve uma tomada de consciência enorme por parte da população, um aprendizado social e político, e a sociedade se organizou como nunca antes tinha se verificado, nem na região nem, talvez, no Brasil. Mesmo não conhecendo em profundidade as outras regiões do Brasil em comparação mais rigorosa, facilmente se constata a importância das mudanças na organização da sociedade civil na Amazônia: grupos sociais, projetos alternativos, movimentos sócio-ambientais que, efetivamente, dominaram o cenário regional, especialmente no período entre 1985 e 1996, anterior aos programas governamentais "Avança Brasil"/ "Brasil em Ação".

A visão dessas mudanças estruturais ajuda, assim, a derrubar certos mitos sobre a região que, é importante destacar, também não se revela homogểnea, nem na sua percepção interna, nem na sua percepção externa. Nós podemos dizer que há percepções diversas ao nível global, ao nível nacional e ao nível local e regional. Aí estão as escalas, percepções, que, por sua vez, como já enfatizamos, estão ligadas a interesses e motivações diversas.

\section{As diferentes percepções da Amazônia}

Em nível global, qual é a percepção dominante em relação à Amazônia? Nunca há uma percepção unificada, é evidente. Mas há uma que é dominante: a da Amazônia como uma grande unidade de conservação, a grande mancha verde a ser preservada para a "saúde" do planeta. O que está sob essa percepção dominante é a questão, a preocupação com o desflorestamento e seus efeitos sobre o clima e o aquecimento do planeta, bem como a perda de biodiversidade. Mais recentemente devemos acrescentar ainda a questão da água, que efetivamente está se tornando um bem escasso e que se torna uma preocupação central no sentido da sua conservação e utilização.

Essa percepção global tem duas raízes muito diversas. Uma ocorre no nível simbólico-cultural, legítima, que vem da questão ambiental, da legitimidade dos ambientalistas, que se preocupam com a salvação mesma do planeta, com os recursos. A outra é econômica e geopolítica, ligada à riqueza natural da Amazônia que, 
com as novas tecnologias, vem sendo valorizada como capital natural, de realização atual ou futura, ligado à biodiversidade - a base do avanço da ciência na biotecnologia, no genoma; além da grande abundância de água, de crescente valor estratégico no mundo. Trata-se, então, do capital natural por um lado, e de Gaia, o peso simbólico, de outro.

Evidentemente, a Amazônia tornou-se também uma região central para a ciência, para a investigação, porque se ela é base da biotecnologia, no avanço da biodiversidade, e da água, então, ela se torna uma fonte de poder, porque, justamente, tem toda essa riqueza potencial, esse capital natural a ser utilizado com as novas tecnologias. É claro que estamos frisando a questão das novas tecnologias mas não podemos esquecer que, simultaneamente, persistem na região, historicamente, os extrativismos, persistem explorações não nobres, predatórias, como a exploração de madeira, a expansão da agropecuária etc.

Essa valorização da Amazônia nos dá uma lição: as redes e fluxos de capital e de informação que sustentam a riqueza circulante do mundo hoje, que sustentam a globalização, não eliminam o valor da riqueza in situ da riqueza localizada no território. E isso é muito importante para a Geografia. Porque muitos afirmam: "os fluxos transfronteiras acabaram com a importância do território, do Estado nacional". Ledo engano. A prática da geopolítica está aí e mostra essa valorização da natureza evidenciando a importância da riqueza localizada. E onde estão localizados os grandes estoques da natureza, hoje? Em três grandes eldorados naturais no mundo contemporâneo: os fundos oceânicos (uma riqueza enorme), ainda não regulamentados e sobre os quais há uma disputa enorme na definição dos mares territoriais; a Antártida, único que está partilhado em torno de soberanias nacionais; e a Amazônia.

Então, esses estoques de natureza são localizados. E percebe-se facilmente que a tecnologia avançada está localizada nos países centrais, enquanto que esses grandes estoques de natureza estão localizados em áreas periféricas - daí o grande embate entre as potências pelo capital natural e pelos estoques de natureza.

A Amazônia é, dessa forma, valorizada estrategicamente como símbolo de vida e capital natural. É importante frisar que o uso dessa valorização, seja como vida seja como capital natural, não pode aparecer dissociada das populações que vivem na Amazônia, porque são elas que têm o saber local, que convivem há séculos com essa natureza e que têm os conhecimentos (sábios), adquiridos historicamente, ao longo do seu convívio na região. Isso também é um ponto importante, porque a maioria das pessoas não tem noção do papel das populações nativas nessa dinâmica.

A maior expressão da importância da natureza como capital natural é o processo que estamos vivendo de mercantilização da natureza. Ao fazer essa reflexão, primeiro temos esta visão através do "mercado do ar": a troca de créditos em função das emissões de gás carbônico. O que é isso senão um mercado do ar, tão discutido em Kioto? Quer dizer, os países altamente poluidores fazem investimentos na conservação ou regeneração de florestas e, com isso, ganham crédito para continuar 
poluindo nos seus países. Aqui, podemos recorrer a Karl Polanyi (2000[1944]), quando mostra que, no século XIX, , no processo de industrialização, foram criadas mercadorias fictícias, porque não foram geradas com o objetivo de venda no mercado. Mas, embora fictícias, elas geraram mercados reais. Ele se refere, por exemplo, ao mercado da terra. Ora, diz o autor, o que é terra senão natureza? Não foi produzida com o objetivo de venda no mercado, mas, ao se tornar uma mercadoria fictícia, gerou mercado real. Outro exemplo: a organização dos mercados de trabalho no século XIX. O que é o trabalho senão vida? Diz Polanyi: vida não foi gerada como mercadoria, mas se tornou mercadoria fictícia e gerou mercados reais. E finalmente o dinheiro, que também foi gerado por todos os interesses, pelos bancos, e tornou-se uma mercadoria fictícia, gerando o mercado do dinheiro.

Polanyi chama a atenção para esses processos nos séculos passados e estamos chamando a atenção, hoje, porque esse processo de mercadorias fictícias e mercados reais somente pode ser controlado, um pouco, pelos movimentos da sociedade que se organizaram desde então. Polanyi está chamando a atenção de que esses mercados não podem ser deixados à sua sorte pelas leis próprias a eles. Na verdade, a sociedade gerou os sindicatos, os movimentos de defesa de todos esses mercados reais criados com mercadorias fictícias. Então, não é o mercado que vai poder controlar tudo isso, e sim a sociedade. A responsabilidade de fazer a regulação e de fazer os controles desses mercados cabe à sociedade. Assim, temos hoje o mercado do ar (troca de "créditos de carbono"), o mercado da vida (com a questão da biodiversidade, a busca das matrizes genéticas e do direito da propriedade intelectual), e o mercado da água, que está em gestação com as primeiras reuniões ao nível internacional. São os foros internacionais que criam o mercado e tentam fazer a regulação, mas a sociedade tem de estar alerta, no sentido de fazer ela própria essa regulação.

E é difícil impedir a formação desses mercados. Mas o que se pode fazer é influir e pressionar em favor da sua regulação. O que acontece hoje envolve várias questões: uma questão ética, pouco comentada. O fato de países poderem reflorestar, criar florestas aqui e continuar poluindo alhures... Há uma questão social também embutida, porque muitos desses reflorestamentos não se fazem respeitando as demandas das sociedades que vivem nessas florestas; configura-se uma atitude extremamente paternalista, como já existem em muitos casos no Brasil. Igualmente, há uma questão ambiental, porque, muitas vezes, no caso de reflorestamento, não se usam as espécies nativas mas sim espécies de fora que não se sabe bem como irão reagir naquele lugar. E, ademais, existe a questão geopolítica, porque floresta é território. É possível privatizar uma empresa, e criar outra, mas não se cria outro território. Penso que é uma questão séria, porque privatizar floresta é privatizar território. Somente se cria outro território, como disse FH, pela guerra. Mas essa é uma hipótese que não está na minha cogitação.

O desafio do desenvolvimento regional da Amazônia não se esgota na problemática global. Estou sugerindo que isso é uma percepção (com ações dela decor- 
rentes) dominante em nível global. Há um discurso ambientalista, mas, na verdade, sob o discurso, jazem interesses econômicos e geopolíticos, há o mercado se formando em relação aos elementos da natureza.

Mas, insisto, não se esgota a problemática da Amazônia em nível global. Em nível nacional, qual é a percepção dominante da Amazônia, considerando-se inclusive as dissidências? Parece-me que ainda é a da fronteira de recursos. Ou seja, a Amazônia como área de expansão da economia e da sociedade nacional é a visão dominante. Essa questão da visão em nível nacional nos remete a outra - que é a do interesse nacional. Interesse nacional que estava muito desleixado, pouco ou nada dele se falava. Era até feio, porque não tinha mais Estado-nação. Logo, não tinha interesse nacional, tema que agora está retornando. A questão se coloca não apenas para nós, que, no momento, estamos diante de uma eleição, como para o mundo todo, inclusive com a produção de uma bibliografia nova sobre o interesse nacional. Mas, o que vêm a ser os interesses nacionais? Conjunto de valores da sociedade historicamente construído e condicionado por situações econômicas e geopolíticas. Acredito que a busca do desenvolvimento econômico é um valor, historicamente, no Brasil. A busca de autonomia, sem dúvida, também é um valor, embora, via de regra, essa busca tenha levado a tratados e acordos que conduziram a uma autonomia relativa. Quanto à paz, é também um valor historicamente construído no Brasil no âmbito das relações externas e existe, no Brasil, um certo convívio pacífico em termos de diversidade cultural, apesar das imensas desigualdades sociais.

Por fim, eu acrescentaria um outro valor: a territorialidade. Historicamente, é um valor da sociedade brasileira, não somente por causa da geopolítica, dos governos, desde a colônia, mas porque, nos próprios movimentos sociais, perpassa a questão da territorialidade. Poderiam ser indicados: Canudos, os quilombos, todos os movimentos, até de resistência revolucionária; os territórios indígenas, as Reservas Extrativistas... A questão territorial encerra um valor, no caso do Brasil e, repito, não apenas do ponto de vista da geopolítica governamental. É lícito questionar o que está acontecendo com esses valores historicamente estabelecidos. Estarão sendo alterados pela rápida mudança em curso na sociedade brasileira? Não se pode perder de vista a sociedade com suas demandas, pressões e conquistas de cidadania. Atualmente, no interesse nacional, incorporam-se muitas das demandas da cidadania, inclusive a questão ambiental, direitos do cidadão, dentre outros, que estão mudando o conteúdo do interesse nacional. E outro elemento que está sendo introjetado é a questão da estabilidade do entorno na América do Sul, hoje uma questão fundamental para o Brasil. Voltarei a isso mais adiante. Deve-se reconhecer que esse processo repercute na Amazônia.

\section{Políticas para a Amazônia}

A mudança do conteúdo do interesse nacional, rebate na Amazônia em duas políticas nacionais absolutamente paralelas e conflitantes: uma delas é a política 
ambiental do Ministério do Meio Ambiente - política que foi desenvolvida, sem dúvidas, por pressão internacional e nacional dos grupos sociais que se organizaram e também por respostas do governo brasileiro.

Deve-se pensar a importância dessa política ambiental. Considero que tivemos avanços. A legislação ambiental brasileira é considerada das mais avançadas do mundo. Penso que a política ambiental, em dez anos, teve grandes conquistas, muito ao contrário do que a mídia difunde. A demarcação dos territórios indígenas não é fato desprezível. Trata-se de um problema histórico nø Brasil. É algo fantástico, de conquista, da luta das sociedades e dos grupos indígenas, que vêm tendo seus territórios demarcados. Vale registrar que alguns grupos indígenas são dos mais "espertos" que existem no Brasil; têm uma inteligência impressionante, um aprendizado rápido, sem destruir a sua cultura. Destacam-se, no meu entender, em relação a outros grupos da Amazônia. Parece que vamos nos indianizar de novo, inclusive porque muitos grupos estão tendo uma taxa de crescimento demográfico que é o dobro da taxa de crescimento da média brasileira, 3,5\%, enquanto a média nacional é de $1,7 \%, 1,8 \%$. É fantástico. Às vezes penso que as pessoas não dão valor ao que de fato ocorre em termos de mudança na sociedade brasileira.

Além disso, multiplicaram-se unidades de conservação de vários tipos. Modelos e conceitos novos, como é o caso das reservas extrativistas - uma forma de luta, um modelo de gestão de território dos seringueiros, uma verdadeira reforma agrária na área extrativista. Torna-se fundamental a experiência das unidades de conservação. Em conjunto, hoje, $22 \%$ de áreas indígenas e $6 \%$ de unidades de conservação do território amazônico estão sob essa tutela conservacionista. E há um projeto do governo federal, já em curso - o Projeto ARPA, que visa a ampliar a área protegida da Amazônia em 10\%. Assim, ter-se-á mais de 30\% do território amazônico como área protegida. Fora isso, existem múltiplos projetos, centenas de projetos alternativos de comunidades, que lidam com a floresta, têm práticas diferenciadas e distintos usos dos recursos da natureza. Dentre as iniciativas de proteção da natureza destacam-se também os corredores ecológicos, corredores imensos, com extensão maior do que vários países europeus juntos. Na minha opinião, trata-se de algo significativo que se vem realizando no país.

Uma característica a ser destacada é que todos os projetos ambientais se desenvolvem com a cooperação internacional. Eu diria que existem, hoje em dia, três grandes tipos de projetos com cooperação internacional:

1) Os clássicos, que são os projetos bilaterais de cooperação internacional;

2) Os grandes projetos voltados para o meio ambiente, com aliados poderosíssimos. Exemplos:

a) Programa piloto para Proteção das Florestas Tropicais (PPG-7), parceria do Brasil com o G-7, União Européia e Banco Mundial.

b) O LBA (Large Scale Biosphere-Atmosphere Experiment in the Amazon), cujo grande parceiro é a NASA. 
c) O PROBEM, projeto que envolve uma série de laboratórios estrangeiros e nacionais, além de empresas, voltado para o desenvolvimento da biotecnologia, que está sendo implantado em Manaus. É outro grande projeto com grandes parcerias, mas estagnado por impasses políticos.

3) Finalmente, vale destacar as parcerias vinculando o local ao global que ocorrem graças às redes de telecomunicações, viabilizando o apoio de parceiros externos. Assim, por um lado, essas parcerias viabilizaram os projetos e as lutas, como foi o caso de Chico Mendes, por exemplo, que é o mais conhecido. Mas, por outro lado, também há uma ingerência externa. Muitas vezes as comunidades são cooptadas e a luta pela terra, pela sobrevivência, acaba transformando-as em "sentinelas da floresta". Então, há uma certa mudança na luta inicial, nos objetivos iniciais de resistência, de luta de defesa da terra. É sutil. E não quero insinuar que os projetos comunitários não possam ter também essa função, mas acho que essa, sinceramente, não era a fundamental.

A cooperação internacional é fundamental. Ninguém faz nada no mundo, hoje, sem a cooperação internacional. Não adianta xenofobismo. Porém, a cooperação precisa ter regulação, e aí a sociedade joga importante papel. Tem que se estabelecer as regras do jogo, porque o que vem acontecendo na Amazônia é uma autonomia excessiva da cooperação internacional, ocorrendo abusos inaceitáveis. Sabe-se que o Ministério da Ciência e Tecnologia está tomando uma série de providências no sentido de robustecer as regras a fim de reduzir essa autonomia que têm os parceiros em relação à Amazônia.

Retomando o ponto sobre as políticas paralelas e conflitantes na Amazônia, emerge uma segunda: a política de infra-estrutura. Pode-se reportar aos principais Eixos de Integração do programa "Avança Brasil", que começou com o programa "Brasil em Ação", em 1996. Basicamente, enfocam infra-estruturas, uma estratégia antiga de ocupação da Amazônia, porém muito mais sofisticada em termos logísticos porque usa sistemas intermodais de transporte, com eixos hidroviários e estradas. Daí decorre a polêmica porque são conflitantes as políticas e muitos desses eixos vão afetar imensas áreas florestais, que abrigam, inclusive, territórios indígenas e unidades de conservação. Além disso, seccionarão essas massas de florestas contíguas e contínuas, abrindo brechas na floresta, tornando-a descontínua, permitindo a expansão de frentes e potencializando o desmatamento regional.

Cabe indagar se é possível transformar os eixos, em vez de elementos de predação, em elementos de novas oportunidades. Penso que é possível, se houver políticas complementares, medidas adequadas. Cabe à sociedade desempenhar ativamente seu papel. E ela já fez uma pressão enorme. Logrou, em apoio ao Ministério do Meio Ambiente, a efetivação de o BNDES fazer uma licitação para análise do impacto dos eixos na Amazônia. Essa licitação já foi realizada, mas não produziu resultados até o momento. 


\section{A dinâmica territorial regional}

Bem, retornemos à questão das diferentes perspectivas em relação à Amazônia. Em nível regional e local, a Amazônia é percebida como um espaço de projeção para o futuro, de novas oportunidades, de alternativas, de possibilidades de ascensão na qualidade de vida, por diferentes grupos sociais, cada um com seus projetos que registram as diferentes demandas locais, certamente influenciadas por ações nacionais e globais. E isso se traduz, na região, por uma dìnâmica de grande velocidade de transformação.

Citarei alguns elementos dessa transformação. Senão vejamos:

a) Em relação ao povoamento regional: um dos aspectos mais flagrantes e importantes de ser reconhecido, na Amazônia, é a questão da urbanização. Lá ocorreu o maior crescimento urbano de todas as regiões do país, porque partiu quase do "zero". É um crescimento muito grande, com quase $70 \%$ da população, no ano 2000, vivendo em núcleos urbanos.

Discordo de alguns critérios e argumentos tradicionalmente utilizados para se tratar o processo de urbanização no Brasil, que negam a atribuição dos conceitos de urbano a núcleos pequenos e sem equipamento. Discordo, porque a urbanização tem dois níveis: um é o nível pontual, concreto, do núcleo urbano em si. O outro é o da urbanização que se dá pela inserção da população nos valores urbanos. Esse processo é também um processo de urbanização, mesmo que a população possa viver no campo. Quer dizer, além dos núcleos urbanos em si, tem-se toda essa inserção, introjeção dos valores urbanos na população da Amazônia. E isso por quê? Pelas redes de telecomunicação, pela alta mobilidade espacial da população e pela própria urbanização. Os valores urbanos realmente foram absorvidos, devido, inclusive, à polivalência daqueles que trabalhavam na cidade e no campo.

Por outro lado, é importante notar que tem havido crescimento das cidades de 50 mil habitantes e também naquelas de 20 mil. E isso reduz a primazia histórica de Belém e Manaus. Antigamente, pode-se generalizar, somente cresciam Belém e Manaus. Agora crescem, também, as cidades de 50 e 100 mil habitantes, além das muito pequenas, que são as mais numerosas.

b) Em relação à migração, hoje, trata-se, flagrantemente, de uma migração intraregional. Não se trata mais daquela migração que vinha de outros estados do Brasil inteiro. E mais: novidade, migração para as fronteiras políticas, gerando movimento, por exemplo, nas fronteiras do Brasil para a Güiana Francesa, já que lá os setores de saúde e de educação são gratuitos, um movimento que tende a estender influência francesa pelo Amapá.

c) Outro elemento importante da dinâmica territorial regional é o uso da terra, podendo-se reconhecer quatro processos na Amazônia: 
1) Reprodução do ciclo de expansão da pecuária, exploração da madeira, desflorestamento e avanço da fronteira. Isto está se reproduzindo tanto na área já ocupada quanto na área de floresta (talvez em menor escala).

2) Um segundo diz respeito ao modelo sócio-ambiental - uma novidade dos anos 90 -, representado justamente por esses projetos alternativos, de diferentes tipos, aos quais já me referi, que ocorrem em áreas florestais, em áreas já povoadas. É Resex, é pequeno produtor, é índio. Então, são modelos sócioambientais inovadores, porque buscam alternativas de uso da natureza e do território. Trata-se de práticas locais que estão buscando e colaborando para a solução de um problema global, qual seja, a conservação da biodiversidade, a qual depende de soluções locais.

3) Outro uso da terra a ser registrado é a expansão da agricultura capitalizada, representada principalmente pela soja. Ela vem do Mato Grosso e adentra pelos cerrados, campos e áreas de pastagem desflorestadas. O maior risco é que avance sobre a floresta; existe mesmo medo, embora se diga que "não", que há "umidade demais"... A discussão é intensa, mas o risco parece ter sentido. Deve-se tomar cuidado, face à contradição da globalização: por um lado, se fala em Programa Piloto para Proteger a Floresta. Por outro, a Europa, ao subsidiar os seus agricultores, impede que eles plantem soja para alimentar os seus porquinhos. Então, todo mundo estimula a expansão da soja no Brasil. Contradições da globalização...

4) Daí outra novidade: são os chamados Econegócios, porque, agora, todo mundo se convenceu de que é muito importante proteger a natureza, mas que assegurar o lucro ainda é fundamental. O modelo sócio-inovador é um sucesso político, mas, economicamente, não o é; apresenta mil problemas. Não tem acesso ao mercado, são difíceis a comercialização e a capacitação para gerenciamento do projeto. Então, voltam-se para o econegócio ou ecobusiness. Tudo indica que agora existem os dois níveis. Os econegócios são dos pequenos, que estão fazendo artesanato, polpa de açaí, cupuaçu, algo mais modesto. E o ecobusiness são dos grandes fundos de investimento, voltados, por exemplo, para o açaí em Marajó, no Baixo Amazonas, exportando para a Europa em termos empresariais, com carteira assinada para todos os trabalhadores. Outro exemplo, é o da madeira certificada, atividade bastante lucrativa porém muito custosa.

Esses seriam os quatros grandes componentes do uso da terra, no momento. Evidentemente, excetuando-se as unidades de conservação e as terras indígenas, já referidas.

\section{Uma nova geografia amazônica}

O penúltimo ponto a que vou me referir é que, com esse processo, delineia-se uma nova geografia amazônica. A estratégia decisiva, no meu entender, serão os 
eixos de integração e desenvolvimento. É (ou seria) possível compatibilizar interesses globais, nacionais e locais, regionais? Esta é uma questão, como também a de como compatilizar aquelas duas políticas paralelas e conflitantes.

A geografia política problematiza a dimensão territorial. Visualizei até aqui um cenário da nova geografia amazônica em macro-regiões, reconhecendo que é pelo território que se efetiva a ação política, a qual incide retroativamente sobre ele. $\mathrm{E}$ reconhecimento do território pode ser uma saída no sentido de estabelecer diferentes prioridades políticas. Então, tratar-se-ia de uma única diretriz política com especificidades para as diferentes macro-regiões dentro da Amazônia.

Podem-se distinguir, assim, três grandes macro-regiões na Amazônia, com características diversas e onde deverão incidir políticas diferenciadas.

A primeira é a Amazônia Oriental ou Meridional. Estou reunindo-as propositadamente, porque este espaço não é mais fronteira. E, a rigor, acredito que não seja mais Amazônia. Maranhão nunca foi Amazônia. Tocantins nunca foi Amazônia. Mato Grosso também nãc. ^ ^ ^ııużônia Legal foi uma construção geopolítica. Não tem nada a ver com os ecossistemas, nem com a cultura. E, hoje em dia, estas áreas estão ocupadas e povoadas. Sem dúvida, houve grandes trechos que foram desflorestados: sudeste e sul do Pará, Rondônia, norte do Mato Grosso. A fímbria da floresta foi retirada, mas não o essencial da Amazônia. A construção geopolítica da Amazônia Legal foi apagada pela prática social,na minha visão. Faço questão, igualmente, de suprimir dessa área os nomes que lhe dão: de "arco do fogo" e de "área degradada". Eu levanto o seguinte ponto: o Rio de Janeiro foi pântano. Nem por isso insiste-se em dizer "o pântano do Rio de Janeiro". Piazza Navona foi um pântano; hoje ela é Piazza Navona. Ninguém continua a falar do pântano. Com relação à Amazônia é semelhante: existiram florestas que foram retiradas, mas essa macro-região hoje é uma área povoada, de povoamento em consolidação. Acabouse! Na minha opinião, não há que se referir a "arco do fogo" e a "área degradada", porque isso dificulta a visão da realidade da própria área. Inclusive, quanto a grande parte do cerrado de Mato Grosso, riquíssima em soja, não tem sentido designá-la "arco do fogo" e "área degradada". Então, proponho essa mudança.

Trata-se da área de economia mais dinâmica da região. Tanto em pecuária, em mineração, soja. Deve-se também prestar atenção nessa área à enorme concentração de assentamentos rurais do Incra. É preciso garantir sua permanência. Qual seria a política para essa área? A de uma política de consolidação das áreas produtivas, que produzem sem depredar a natureza; consolidar, mudar certos métodos, como já se está tentando nas imediações de Marabá - pecuária melhorada, por exemplo - e recuperar também áreas que foram realmente devastadas, desflorestadas e queimadas. Vê-se que a consolidação é um elemento fundamental, porque é hoje, de fato, uma área extremamente dinâmica. Inclusive, diga-se, o Tocantins é um estado de passagem, que tem um dinamismo incrível, além de Carajás, e tudo o mais que ele comporta. Então, para mim, isso não é mais fronteira; já é uma área de povoamento em consolidação, isto para não dizer que já está consolidada. 
A outra região, que estou reconhecendo, é a Amazônia Central, que abrange grande parte do Estado do Pará, estendendo-se até o novo corredor da estrada Porto Velho-Manaus, e sua seqüência até a Venezuela; está-se abrindo, sem dúvida alguma, um novo corredor dentro da floresta. Aí temos um risco, realmente, de haver uma frente de expansão maior. Essa área é a mais vulnerável na Amazônia, porque nela haverá maior número de eixos que aceleram a velocidade de transformação, e nela existem imensas massas de florestas contíguas com unidades de conservação e com terras indígenas. Ocorre que esses eixos seccionarão essas matas. Então, o risco é maior. Do que se precisa em termos de política, se é a área mais vulnerável à velocidade de transformação? Qual deveria ser a política? Acelerar o ritmo da política conservacionista para contrabalançar esse risco, com demarcação de terras indígenas, com unidades de conservação. E uma outra coisa importantíssima: estradas vicinais, para que as populações locais também tirem partido da nova circulação regional. Caso contrário, os corredores somente exportarão soja, e a população local não usufruirá nada. Então, é preciso prever a conservação e a fluidez. Fluidez, para que as populações indígenas e extrativistas também possam utilizar esses eixos, porque, em geral, eles passam pela região completamente isolados da população local, isto é, sem a perspectiva efetiva de inseri-la ou englobá-la.

E, finalmente, a Amazônia Ocidental é a que fica para oeste daquele novo corredor ao qual me referi. E é a área que ainda não foi afetada por eixes de integração e desenvolvimento. Então, é uma área cuja dinâmica ainda é comandada pelo ritmo da natureza; não tem a velocidade, o risco que terá a Amazônia Central com os eixos. Ainda é o domínio da natureza. Nela está concentrada praticamente toda a riqueza da região, sem contar que é também a área do narcotráfico, do contrabando, das maiores fronteiras políticas. Impõe-se também a pergunta: qual é a política para esta área? Vigilância é um termo fundamental para a Amazônia Ocidental. Em termos não apenas das atividades ilícitas como da proteção do meio ambiente, já que ela não foi depredada. Isso significa vigilância acompanhada de desenvolvimento sustentável (tenho restrições a este termo, mas enfim...). O que se poderia prever para essa região em termos de desenvolvimento? É bom destacar que a expressão "comandada pelo ritmo da natureza" não significa que a área ficará parada no tempo. De forma alguma. A Amazônia Ocidental é a que tem o grande potencial de implementar realmente um modelo de desenvolvimento sustentável, porque ela ainda tem a floresta.

Para mim, desenvolvimento sustentável não se reduz àquela idéia de small is beautiful. Sob o meu ponto de vista, desenvolvimento sustentável implica em utilizar os recursos de uma forma conservacionista. A partir daí, pode-se alcançar nichos de mercado, altamente sofisticados, e que, de certa maneira, já é algo que está ocorrendo na região, pois já começaram investimentos em madeira certificada. Existem experimentos, por exemplo, em Boca do Acre, da borracha vegetal, que vende para a famosa Hermés, na França. É um comércio considerável. São produtos 
que poderão ser utilizados de forma conservacionista e que podem ter um alto valor do mercado internacional. Deve-se aprofundar nas pesquisas, em novas descobertas. Alguns produtos já estão aí, mas há outros, possibilidades de pesca, inclusive.

\section{A Amazônia frente à integração continental e à globalização}

Por fim, quero falar sobre uma nova escala que se apresenta para a Amazônia: a escala continental. Falei da global, nacional, local. E, agora, tem-se a Amazônia transnacional. Não podemos mais pensar a região sem pensar na Amazônia sulamericana. Inclusive Manaus deverá ser o centro da Bacia Amazônica, nessa região ocidental, como, talvez, Belém, que perde muito do seu espaço para a ação de Goiânia e Brasília, pode vir a estender sua área de influência até o Suriname e a Guiana Francesa, via Macapá.

Assim, Manaus tem uma posição estratégica em relação à Bacia Amazônica. E, hoje, está havendo todo um movimento de retomada do famoso Tratado de Cooperação Amazônica, o qual foi estabelecido em 1978, mas ficou no papel e praticamente nada se fez, a não ser criar uma Unamaz, que é interessante: Universidades Amazônicas. Porém, em termos de cooperação, não houve nada de significativo. Agora, esse tratado está sendo resgatado. Um fato importante é que a Secretaria do Tratado foi instalada permanentemente no Brasil, añtes a Secretaria girava em rodízio nos diferentes países sul-americanos.

Por que, de repente, resolve-se resgatar o Tratado de Cooperação Amazônico, que estava parado no tempo? Duas coisas eu penso a este respeito. Do ponto de vista do interesse nacional, a integração latino-americana é fundamental hoje e, particularmente, para o Brasil, no sentido da ampliação de mercados, de cooperação, complementaridade, sobretudo energética. É o caso do Mercosul, com dificuldades para se consolidar. Em compensação, a Alca se afirma cada vez mais. A Alca - uma pressão dos Estados Unidos, "a América para os americanos" - e o Mercosul, que era um projeto regional e que está "balançando", hoje, em grande parte por causa das dificuldades da Argentina. Mas não é só isso.

A outra razão para a integração amazônica, é o que está acontecendo neste início do século XXI,em termos de mudanças globais: a América Central e a fachada do Pacífico da América do Sul estão sofrendo um processo de militarização crescente. Existem localidades de operação avançada - este é o nome para evitar chamar de bases - desde a Costa Rica, Curaçao, Panamá, Colômbia, Equador, Bolívia e Chile (e Alcântara). Mas a pressão para colocar bases no território brasileiro era muito grande, muito maior. E, de certa maneira, houve uma resistência por parte do Brasil. O projeto Sipam-Sivam, assim, foi uma resposta do governo brasileiro a essa pressão.

Enquanto a crise financeira abalou a Argentina, mais de uma tentativa de golpe ocorreu na Venezuela, configurando um verdadeiro cerco ao território brasileiro. 
As pressões são enormes: políticas, econômicas, científicas, financeiras. Então, deve-se levar isso em conta, também. Parece-me que, de repente, tornamo-nos uma ilha cercada de bases por todos os lados. E qual é a incidência da globalização no Brasil?

No Brasil, a incidência da globalização se faz pela cooperação internacional. Parceiros poderosos, com redes locais/globais, mas que têm o seu lado positivo, pois essa cooperação internacional é um instrumento de mudança se houver negociação adequada. E ela tem sido um instrumento de mudança, principalmente em relação ao padrão de ocupação da Amazônia que se tinha antes. Ela trouxe, realmente, viabilidade para os projetos alternativos, uma outra forma de organização da sociedade. Isso é extremamente importante, é um lado extremamente positivo. Por outro ângulo, há que fazer a regulação, as regras do jogo para o controle da informação. Para onde vai a informação produzida nos grandes projetos?

O que estamos vivendo é um outro elemento da globalização de que é preciso falar: a globalização da pesquisa. Existe o International Council of Scientific Union, que agrega todas as organizações científicas internacionais de todas as disciplinas. E tem um projeto imenso, que se chama Global Environmental Change, que começou tratando da parte física dos oceanos, do clima, mas que hoje em dia é um subprograma de dimensões humanas. O que acontece? Pesquisadores de diferentes países são pinçados para participar desses projetos e eles fazem parceria com pesquisadores de outros países e ficam satisfeitos, porque têm apoio financeiro, têm recursos para tudo o que é valorizado nessa área. Porém, quem fica com o conjunto da informação? Os pesquisadores nacionais não têm. Eles têm a informação sobre o seu projeto. Mas se é "global", tem um parceiro aqui, outros acolá. O conjunto de informação, I don't know. Falo essas coisas porque somos da Universidade, somos pesquisadores. Devemos fazer parcerias? Sim. A cooperação internacional é importante? Sim. Não há dúvida alguma. Porém temos de saber negociar! Nós não sabemos negociar. É preciso evitar a xenofobia sem motivos óbvios. É preciso aprender isso, pois estamos vivendo um processo de globalização. E, se não se aprende, como fazer a regulação e estabelecer as regras do jogo que nos interessam? 